\title{
Terapias hemodialíticas e transplante renal: desafios e sentimentos vivenciados pelo paciente na fila de espera
}

Hemodialytic therapies and kidney transplantation: challenges and feelings experienced by the patient in the waiting line

Terapias hemodialíticas y trasplante de riñón: retos y sentimientos experimentados por el paciente en la línea de espera

Elisandra Santos Flores ${ }^{1 *}$, Lúcia Fabiane da Silva Luz ${ }^{1}$, Márcia Dornelles Machado Mariot ${ }^{1}$, Dayane de Aguiar Cicolella1.

\section{RESUMO}

Objetivo: Identificar como o paciente em terapia hemodialítica vivencia o processo de espera para 0 transplante. Métodos: Trata-se de uma pesquisa qualitativa exploratória e descritiva realizada em uma clínica de hemodiálise em um município do Rio Grande do Sul. A coleta de dados foi realizada com pessoas diagnosticadas com Insuficiência Renal Crônica (IRC), em terapia hemodialítica e que aguardavam transplante renal. Foram realizadas entrevistas no ano de 2020, em ambiente reservado, gravadas em áudio, com duração de 10 minutos, guiadas por instrumento e transcritas. O fechamento amostral ocorreu por saturação teórica e a análise dos dados baseou-se na análise temática proposta por Minayo MCS (2014). Resultados: Os relatos permitiram identificar as principais dificuldades e anseios daqueles que aguardam transplante renal, destacando o período de fila de espera. A partir dos relatos coletados foi possível a formação de duas categorias temáticas: "a rotina da hemodiálise que fortalece a esperança de sair da máquina" e "a frustração da espera em meio a uma pandemia". Conclusão: Permitiu-se compreender sentimentos e anseios de pessoas em lista de espera por um transplante renal, destacando a esperança pela doação de um órgão e libertação da máquina de hemodiálise como principais sentimentos.

Palavras-chave: Diálise renal, Transplante de rim, Lista de espera.

\section{ABSTRACT}

Objective: To identify how the patient undergoing hemodialysis therapy experiences the waiting process for transplantation. Methods: This is an exploratory and descriptive qualitative research carried out in a hemodialysis clinic in a city in Rio Grande do Sul. Data collection was performed with people diagnosed with Chronic Kidney Failure (CRF), undergoing hemodialysis therapy and awaiting kidney transplantation. Interviews were carried out in 2020, in a private environment, recorded in audio, lasting 10 minutes, guided by an instrument and transcribed. The sample closure occurred by theoretical saturation and data analysis was based on the thematic analysis proposed by Minayo MCS (2014). Results: The reports allowed us to identify the main difficulties and anxieties of those awaiting kidney transplantation, highlighting the waiting list period. From the collected reports, it was possible to form two thematic categories: "the hemodialysis routine that strengthens the hope of getting off the machine" and "the frustration of waiting in the middle of a pandemic". Conclusion: It allowed understanding the feelings and anxieties of people on the waiting list for a kidney transplant, highlighting the hope for the donation of an organ and the release of the hemodialysis machine as the main feelings.

Keywords: Kidney dialysis, Kidney transplant, Waiting list.

${ }^{1}$ Cesuca Centro Universitário, Cachoeirinha - RS. *E-mail: e.lisandraflores@hotmail.com 


\section{RESUMEN}

Objetivo: Identificar cómo el paciente sometido a terapia de hemodiálisis experimenta el proceso de espera para un trasplante. Métodos: Se trata de una investigación cualitativa exploratoria y descriptiva realizada en una clínica de hemodiálisis de una ciudad de Rio Grande do Sul. La recolección de datos se realizó con personas diagnosticadas de insuficiencia renal crónica (IRC), en tratamiento de hemodiálisis y en espera de trasplante renal. Las entrevistas se realizaron en 2020, en un ambiente privado, grabadas en audio, con una duración de 10 minutos, guiadas por un instrumento y transcritas. Resultados: Los informes permitieron identificar las principales dificultades y ansiedades de los que esperan un trasplante renal, destacando el período de lista de espera. A partir de los informes recopilados, fue posible conformar dos categorías temáticas: "la rutina de hemodiálisis que fortalece la esperanza de bajarse de la máquina" y "la frustración de esperar en medio de una pandemia". Conclusión: Permitió comprender los sentimientos y ansiedades de las personas en lista de espera para un trasplante de riñón, destacando la esperanza por la donación de un órgano y el lanzamiento de la máquina de hemodiálisis como sentimientos principales.

Palabras clave: Diálisis renal, Trasplante de riñón, Lista de espera.

\section{INTRODUÇÃO}

A perda progressiva e irreversível da função renal (glomerular, tubular e endócrina) em sua fase mais avançada denomina-se Insuficiência Renal Crônica (IRC), patologia esta onde os rins não conseguem manter o equilíbrio hidroeletrolítico do indivíduo. A doença renal intervém negativamente na condição de vida dos pacientes, chegando ao alcance de causar uma grande debilitação a estas pessoas, além de atribuir a elas restrições nos campos físico, psíquico e social, exigindo apurado esforço para conseguirem suportar e se adequarem às impetras que o tratamento oferece (RODRIGUES KA, et al., 2020).

O Chronic Kidney Disease Epidemiology Collaboration (CKD-EPI) define a doença renal em cinco estágios que são avaliados pela função da medida em $\mathrm{ml} / \mathrm{min} / 1,73 \mathrm{~m} 2$. Os resultados dessa equação classificam os estágios da IRC nas seguintes categorias: G1 (> 89), G2 (60-89), G3a (45-60), G3b (30-44), G4 (15-29) e G5 (<15), sendo que o G1 representa função renal ainda preservada e os outros estágios representam 0 progresso gradativo para perda da função renal. Já o G5 é a fase considerada insuficiência crônica terminal. Após o diagnóstico da IRC o tratamento tradicional é a hemodiálise, sendo necessário ser iniciado o mais breve possível, evitando-se assim a probabilidade de evoluirem complicações as quais poderão levar 0 paciente a óbito (CASTRO TLB, et al., 2020; BRITO JPF e FERREIRA RCV, 2019).

Segundo a Sociedade Brasileira de Nefrologia (SBN) a prevalência de IRC tem aumentado progressivamente a cada ano, tornando-se um dos maiores problemas de saúde pública da atualidade. Dados da SBN apontam que em 2019 havia cerca de 54.488 mil pacientes em tratamento renal substitutivo, onde 49.558 mil realizavam hemodiálise convencional, o que corresponde aproximadamente a $90 \%$ destes pacientes. No mesmo ano, observou-se aumento casos e 3.306 pacientes foram cadastrados com insuficiência renal. Estima-se que 33.015 pacientes que realizam hemodiálise estejam em fila de espera para o transplante renal (SBN, 2019).

Terapêuticas hemodialíticas compreendem a substituição da função renal, sendo elas: hemodiálise (HD), diálise peritoneal (DP) e transplante renal (TX); contudo, nenhuma delas é considerada uma medida curativa. $\mathrm{O}$ transplante de rim surge como alternativa à pessoa com IRC e quando bem-sucedido, é considerado modalidade terapêutica que proporciona aumento na expectativa de retorno à rotina de vida ao mais próximo do normal, anterior ao surgimento da doença. Promove melhora da autonomia e liberdade do indivíduo, e consequentemente, maior qualidade de vida (FARMI MRV, 2011; VERONESE FV, et al., 2019).

No entanto, o paciente com IRC depara-se com um problema quando opta por umas das Terapias Renais Substitutivas (TRS), podendo haver uma revelação de construção e/ou apropriação de significados que possam trazer consigo conflitos sobre a possibilidade de submeter-se ao transplante renal. Em casos de perda de função renal irrecuperável, deve haver a substituição desta através de diálise ou transplante renal. $O$ transplante tem várias vantagens em relação à diálise por proporcionar uma melhor qualidade de vida sem as restrições associadas à diálise (VERONESE FV, et al., 2019; BARBOSA JT, et al., 2020). 
A qualidade de vida é um conceito multidimensional e, quando relacionada à saúde abrange relato subjetivo de sintomas, efeitos colaterais, funcionalidade em múltiplas propriedades da vida e percepção geral da satisfação em relação com ela. O paciente renal crônico tem uma visão otimista em relação ao transplante como, por exemplo, esperança de uma "nova vida" com mais livre-arbítrio. Em contrapartida, existe o receio diante das inseguranças quanto ao sucesso e estabilidade do transplante (OLIVEIRA LM, et al., 2020; PAULETTO MR, et al., 2016).

Considera-se a importância da identificação dos principais sentimentos e anseios do indivíduo com doença renal crônica, a fim de melhor compreender as suas expectativas. Portanto, a partir da necessidade de conhecer a relação entre "o viver e o esperar" na vida daquele que se encontra em fila de espera para transplante renal, o presente estudo teve como objetivo identificar como a pessoa em terapia hemodialítica vivencia o processo de espera para o transplante.

\section{MÉTODOS}

Trata-se de um estudo qualitativo, exploratório e descritivo. A pesquisa foi realizada em uma clínica de hemodiálise localizada em um município da região metropolitana de Porto Alegre, Rio Grande do Sul/Brasil. A Clínica de Hemodiálise é o local onde pessoas com insuficiência renal crônica realizam o processo de terapia renal substitutiva (TRS), comparecendo três vezes por semana e permanecendo por um período de até quatro horas por dia.

Participaram do estudo 10 pessoas com diagnóstico de IRC, em terapia hemodialítica por um período mínimo de um ano e que aguardam o transplante renal na fila de espera. O fechamento amostral não foi previamente pré-determinado e deu-se por saturação teórica. A saturação constitui-se de uma ferramenta conceitual utilizada para estabelecer ou fechar o tamanho final de uma amostra, por suspensão da inclusão de novos participantes, quando observado pela pesquisadora redundância ou repetição de dados (RIBEIRO J, et al., 2018).

Os dados foram coletados através de entrevistas abertas, gravadas em áudio, posteriormente transcritas e guiada por instrumento norteador, realizadas na própria clínica de hemodiálise em ambiente privado (sala reservada), individualmente e com duração máxima de 15 minutos. Destaca-se que foram observados os cuidados e medidadas de prevenção de transmissão da Covid-19 preconizadas pelo Ministério da Saúde e pela Organização Mundial de Saúde a cerca da situação pandêmica em que se encontramos foram aderidos.

A análise foi realizada conforme proposto por Minayo MCS (2014), através de etapas: pré-análise, exploração do material, tratamento dos resultados obtidos e interpretação.

O estudo seguiu os aspectos éticos de preservação e confidencialidade dos entrevistados, respeitando às Diretrizes e Normas Reguladoras de Pesquisas Científicas do Conselho Nacional de Saúde pela Resolução № 466 de 12 de dezembro de 2012 e foi submetido ao Comitê de Ética em Pesquisa do Centro Universitário Cesuca, aprovado através do parecer $n^{\circ} 4.671 .660$ e CAAE 45467621.0.0000.5665 (MINISTÉRIO DA SAÚDE, 2012).

Os participantes assinaram o Termo de Consentimento Livre e Esclarecido (TCLE) que garante a participação livre e espontânea, sem remuneração, com cessação em qualquer momento da pesquisa e a confidencialidade dos dados coletados. Os diálogos e dados extraídos das entrevistas foram descritos na íntegra e foi garantido ao participante a privacidade, a confidencialidade e o anonimato em todas as etapas do processo da pesquisa. Para a devida preservação da identidade os participantes foram identificados com um código $\mathrm{P}$, referente à participante e seguido número de ordem da realização das entrevistas.

\section{RESULTADOS E DISCUSSÃO}

Participaram da pesquisa 5 homens e 5 mulheres que realizam hemodiálise e aguardam transplante renal em fila de espera. Entre os entrevistados, dois participantes possuíam nível superior completo, um apresentava curso técnico em enfermagem e os demais ensino fundamental completo. A maioria apresentava, em média, 6 meses de tempo em lista de espera e mais de dois anos em hemodiálise. 
Após análise dos dados coletados foi possível desenvolver as seguintes categorias temáticas para interpretação dos dados obtidos, sendo elas: "a rotina da hemodiálise que fortalece a esperança de sair da máquina" e "a fé, a esperança e a frustração da espera em meio a uma pandemia".

\section{A rotina da hemodiálise que fortalece a esperança de sair da máquina}

Quem está na fila do transplante renal enfrenta circunstâncias complicadas que transpõem o processo biológico e essa espera, pode gerar diferentes sentimentos e expectativas ao indivíduo. Tais sentimentos são, por exemplo, impotência, ansiedade, angústia, instabilidade e desmotivação (ROCHA HC, et al., 2018).

Ademais, portador de IRC em hemodiálise acaba estabelecendo uma relação de conflito com a máquina de diálise; se por um lado, ele está dependendo dela para sobreviver, por outro, também é ela que sinaliza sua condição de doente e que é dela dependente (PESTANA JOM, et al., 2014). Os relatos a seguir destacam essa relação entre o equipamento de diálise e a expectativa gerada a partir da esperança de não mais necessitar da rotina da hemodiálise e, consequentemente estar liberto da máquina, são eles:

"A gente chega bem no dia da hemodiálise e após, sai tão fraca, tão ruim. O meu maior sonho é sair dessa máquina. Quando me chamam para seleção de pacientes compatíveis, eu penso: hoje vou sair da máquina, pois são três vezes por semana que tenho que fazer o tratamento. Eu quero poder ficar em casa, porque a gente deixa os filhos, deixa marido, deixa tudo e tem que vir para cá. Eu não gosto, mas é a minha vida e eu dependo dessa máquina para viver" (P9).

"Eu espero que logo consiga transplantar. É uma situação que a gente sabe que leva tempo, pois tem que ter uma compatibilidade maior e melhor. Por mim, posso receber um rim mais novo ou até um pouco mais velho, pois já estou com 37 anos. Assim, a gente vai aguardando, ficando na máquina e na expectativa. Eu sei que vai chegar, minha hora vai chegar. E, durante essa espera, não tenho muito o que fazer. Preciso aguardar e ir fazendo o tratamento correto, pois quando chegar a minha vez de transplantar tenho que estar bem para que ocorra tudo com sucesso" (P8).

Pessoas em IRC estão cercadas pela expectativa de transformação após a realização do transplante como, por exemplo, a melhora da qualidade de vida, o fim da dependência das sessões de hemodiálise e até um possível retorno à antiga rotina, incluindo voltar ao trabalho. A probabilidade de reintegração ao convívio social, retorno aos afazeres ou mesmo a chance de não estar mais exposto aos sintomas agregados à diálise fazem do transplante a fundamental nascente de esperança do portador de IRC (ROCHA HC, et al., 2018).

Nesse sentido, manter a esperança frente à doença crônica é um processo contínuo e essencial, uma vez que é um recurso valioso no enfrentamento dessa condição. Possui um efeito benéfico para a saúde das pessoas, contribuindo para a capacitação da mesma em lidar com situações de crise, manutenção da qualidade de vida e determinação de objetivos saudáveis para a promoção da saúde (FERREIRA C, et al., 2018). Esses sentimentos destacam-se nos relatos abaixo:

"Eu só espero que quando me chamarem dê tudo certo e que já saia funcionando meu rim novo, porque eu escuto que tem gente que ainda demora para funcionar o órgão recebido. Mas, eu sei que quando fizer o transplante vai ser rápido. Eu vou ficar dois ou três dias lá no hospital, uma semana no máximo. Vai dar tudo certo, eu tenho muita esperança” (P6).

"Estou na espera desde novembro e, às vezes, fico um pouco ansioso. Eu quero muito transplantar e quero continuar a minha vida. Tenho uma ansiedade enorme, mas ela é boa. O que mais me preocupa é encontrar um doador compatível. O que mais me motiva é poder passar mais uns anos com a minha filha, passar mais uns anos vivendo bem, além de ter uma qualidade de vida melhor" (P7).

O processo da insuficiência renal crônica e espera pelo transplante é longo e a pessoa passa por momentos distintos. Cada etapa ou cada nova situação apresentada, seja ela boa ou ruim, demanda do paciente a reconstrução dos sentidos deles associados à doença, além de terem que desempenhar novas estratégias para lidar com a proximidade iminente ou não da morte (PESTANA JOM, et al., 2014). 
O suporte espiritual é de grande importância para o enfrentamento da doença e durante o período de espera para o transplante. De certa forma, a religiosidade exerce importante influência, representada como fonte de conforto, esperança, encorajando e, consequentemente, trazendo um bem-estar geral. De fato, contribui e coopera para uma melhor aceitação da atual condição de vida do indivíduo (SOUZA AM, 2015). As falas abaixo podem confirmar essa situação:

"E tem dias que eu penso: não adianta eu desmotivar, estou fazendo tratamento e tenho que ficar bem para a hora que me chamarem para o transplante. Não adianta ter esperança e não seguir o tratamento, pois depois todo esse trabalho será jogado tudo fora" (P5).

"Eu tenho uma esperança que só Deus sabe. Tem dias que eu penso assim: penso que vai ser difícil. Mas, tem outros dias que penso: vai ser hoje ou, que não vai demorar o transplante. A cada dia eu sempre peço que seja logo e que não demore. Na realidade, acaba sendo uma sensação boa o fato de saber que tu não estás esquecido. A equipe lembra de mim quando aparece uma doação de rim e isso é bom, pois alimenta minha esperança" (P1).

O medo relacionado com a doença e com o transplante renal é reforçado pelo paciente, uma vez que a sua vida está em risco diariamente ao lidar com a vinculação da máquina e deste modo, o transplante acaba sendo percebido como um processo restituidor de sua situação de saúde. Enfrentar a doença e os sentimentos que se misturam a ela tornam-se mínimos, sendo o medo da morte a emoção prevalente (FARIAS MS, et al., 2018). Assim, a tentativa de controlar as emoções e o medo da morte se fazem presentes nos relatos dos entrevistados:

"Depois de me sentir mais seguro e conversar com a equipe, eu voltei para lista, para ver se eu consigo fazer o transplante e seguir a minha vida sem a hemodiálise. Mas, agora é diferente. Depois de eu ter estudado para ser técnico em enfermagem fiquei sabendo de algumas coisas e voltei a ter medo de novo, de fazer o transplante. Agora eu decidi que eu vou fazer, se me chamarem. Eu vou com medo mesmo porque o que eu mais quero, principalmente, é sair da máquina. Eu quero poder trabalhar como técnico em enfermagem, pois foi para isso que eu estudei, para poder ter uma qualidade de vida melhor" (P4).

"Meus dias são tranquilos e não tenho medo agora. No começo até tinha um pouco de medo, pois é mais difícil aceitar. Eu ouvia muita coisa, cada pessoa diz uma coisa diferente. Aí, depois que eu entrei para fila de espera, a enfermeira me explicou tudo direitinho e perdi o medo. Agora estou mais tranquilo, mesmo em todo o tempo que estou esperando" (P6).

De acordo com as respostas obtidas nas entrevistas observa-se que, de fato, a esperança pela doação de um órgão compatível destaca-se como o principal sentimento daqueles cadastrados na fila de espera para transplante renal. A esperança coligada à confiança são perspectivas relatadas que sustentam o desejo por abandonar a dependência da hemodiálise. Contudo, existe o enfrentamento do medo e isso reforça a ocorrência de sentimentos negativos como a incompatibilidade ou o não funcionamento do órgão recebido no transplante do rim.

\section{A fé, a esperança e a frustração da espera em meio a uma pandemia}

A espera na lista de transplante, seja por meses ou anos, torna-se frustrante para a maioria dos pacientes. Conviver com a possibilidade de o procedimento ser um fracasso/sucesso, desperta dúvidas em relação a escolha do tratamento. Uma ambiguidade de sentimentos e emoções caracterizam a espera, expressas pelo entusiasmo diante da expectativa em realizar o transplante. Porém, esses sentimentos são acompanhados por momentos de cansaço, desânimo e angústia, marcados pelo indefinido tempo de espera por um doador compatível (PAULETTO MR, et al., 2016). 
"Às vezes eu me sinto um pouco aflito por conta da espera e também, das dúvidas em relação a esse tempo parado. Tu não sabes o que vai acontecer; então acabo ficando aflito e angustiado. Também, há momentos que eu fico mais sereno e vivo um dia de cada vez. Eu vou levando, me cuidando e vou indo do jeito que dá. Mas, o que mais me preocupa durante essa espera é a incerteza e a demora. Entendo todo esse processo que envolve a demora para o transplante. Mas, isso é angustiante porque tu não sabes até que dia que tu vais conseguir esperar. Sei que existem pessoas que estão na fila há mais de 10 anos, isso é muito tempo e, como eu já estou esperando há três anos, isso me preocupa. Me questiono, quanto tempo eu vou ficar? Sei que é ruim ficar muito tempo aguardando, pois o médico já me explicou que a expectativa de vida é maior para quem faz o transplante do quê para quem faz hemodiálise. Então, quanto mais tempo ficar na hemodiálise mais chances eu tenho de adquirir mais problemas" (P3).

"Eu já fui chamado três vezes e foi muito emocionante. Porém, infelizmente não deu certo. Cada vez que me chamavam eu dizia: em nome de Jesus agora vai dar certo, hoje vai dar tudo certo, mas aí não dava. Isso é muito frustrante e as vezes desmotiva" (P9).

"Eu já fui chamado uma vez e depois dessa chamada não deu certo. O rim não foi para mim, pois ele estava com problemas. E então, não foi dessa vez. Eu me senti muito emocionado quando me chamaram, mas depois fiquei triste porque não deu certo. Mas, graças à Deus eu estou aqui aguardando outra chamada e sei que Deus quer que logo eu seja transplantado" (P2).

Segundo Rocha HC, et al. (2018) ocorrem manifestações de certo grau de conformismo em relação à espera, uma vez que, nada pode ser feito para encurtar este tempo. Esse sentimento pode ser observado nas falas abaixo:

"Eu nunca fui chamado pela central de transplante. Mas, o que me dá força é a minha vontade de viver. Somente o que eu sei é que tem um monte de gente na fila de espera para receber um rim e isso, me preocupa um pouco. Aliás, isso é o que mais me preocupa" (P5).

"Até agora não fui chamado nenhuma vez, nem para esperar. Apenas fiz todos os exames solicitados e agora, estou aguardando para ser chamado em algum momento. Enquanto isso, eu vou enfrentando a hemodiálise" (P10).

A Covid-19 teve impacto imediato nas atividades de doação e transplante nos países mais afetados. Em 2020 , no Brasil, houve queda de $13 \%$ na taxa de doadores, tanto por redução nas notificações de potenciais doadores quanto por aumento do número de contraindicações. Essa redução significativa deu-se imediatamente após a declaração da Organização Mundial da Saúde (OMS) sobre a pandemia. Consequentemente, todas as modalidades de transplante foram afetadas, especialmente o transplante de rim, coração e córneas. A redução das notificações está relacionada à diminuição dos acidentes, fato que impacta diretamente nos casos de morte encefálica. Os transplantes renais a partir de doadores vivos também foram suspensos, conforme recomendação do Ministério da Saúde pelo período de transmissão comunitária do SARS-CoV-2 (ARAÚJO AYCC, et al. 2021; GARCIA VD e PÊGO-FERNANDES PM, 2021). Abaixo, seguem alguns relatos sobre o impacto da pandemia no transplante renal:

"Eu vim da minha cidade, lá de Macapá com bastante expectativa, mas daí veio esse problema do Coronavírus e deu uma parada nos transplantes. Mas, eu espero que logo volte tudo ao normal e rezo para eu ser transplantado logo. A minha expectativa é muito grande para acontecer esse transplante" (P2).

"O que mais me motiva é que a doadora vai ser a minha irmã e acho que eu não posso desistir por ela, por ela querer ser a minha doadora e por eu viver uma vida melhor porque o transplante é outra coisa, é vida. Mas, aí veio a pandemia e vamos ter que esperar um pouco mais" (P1). 
Essa redução de atendimentos serve como estratégia de prevenção de infecção pelo SARS-CoV-2, tendendo a segurança dos doadores e pacientes que necessitam aguardar na fila para procedimentos, sejam eles eletivos ou em caráter de urgência (VALERI AM, et al., 2020).

Percebeu-se que os participantes desta pesquisa trazem consigo perspectivas positivas da realização de um transplante renal efetivo, com a esperança de uma melhora na sua qualidade de vida e também, como uma nova chance de retomar sua autonomia. Contudo, necessitam lidar com a frustação da não compatibilidade do órgão a ser transplantado, fato que acarreta retorno à fila de espera. Ademais, o advento da pandemia da Covid 19 contribuiu significativamente para a redução do número de doadores e transplantes, causando desapontamentos e maior tempo em espera.

\section{CONCLUSÃO}

Este estudo permitiu compreender sentimentos e anseios de pessoas em espera por um transplante renal. A esperança pela doação de um órgão compatível destacou-se como o principal sentimento associado à expectativa pela libertação da máquina de hemodiálise. Em contraponto, destacaram-se as frustações relacionadas à incompatibilidade do órgão e redução do número de transplantes mediante a pandemia da Covid 19. Dessa forma, o estudo contribui com informações relevantes sobre o período de espera pelo órgão e enfrentamentos que suscitam diferentes sentimentos no paciente. A partir dos resultados encontrados, sugere-se que novas pesquisas possam ser realizadas em outros espaços com a finalidade de ampliar achados acerca desta temática.

\section{REFERÊNCIAS}

1. ARAÚJO AYCC, et al. Declínio nas doações e transplantes de órgãos no Ceará Durante Pandemia da COVID-19: Estudo Descritivo de Abril a junho de 2020. Epidemiologia. Serv. Saúde, 2021; 30:1-7.

2. BARBOSA JT, et al. Transplante Renal: Mecanismo de Rejeição, Terapia Imunossupressora e Métodos Diagnósticos. Caderno Saúde e Desenvolvimento, 2020; 9: 1-14.

3. BRITO JPF, FERREIRA RCV. Doença Renal: Do Diagnóstico ao Transplante. Saúde Unitoledo, 2019; 3:25-36.

4. CASTRO TLB, et al. Função Renal Alterada: Prevalência e Fatores Associados em Pacientes de Risco. Revista Cuidado, 2020; 11: 1-12.

5. FARIAS MS, et al. Sentimentos de Pessoas em Hemodiálise que Esperam por um Transplante Renal. Revista Brasil Saúde, 2018; 22: 357-362.

6. FARMI MRV. Manual de diálise para enfermagem. 2 ed. Rio de Janeiro: Medsi, 2011.

7. FERREIRA C, et al. Avaliação de Esperança e Resiliência em Pessoas em Tratamento Hemodialítico. Revista de Enfermagem da UFSM, 2018; 4: 702-716.

8. GARCIA VD, PÊGO-FERNANDES PM. O transplante de órgãos e a COVID-19. Diagn Tratamento. 2021;26(3):93-6.

9. MINAYO MCS. O desafio do conhecimento: Pesquisa qualitativa em saúde. São Paulo: Hucitec, $2014 ;$ p. 408.

10. MINISTÉRIO DA SAÚDE. Conselho nacional de Saúde. Resolução № 466, de 12 de dezembro de 2012. Brasil, 2012. Disponível em: http://bvsms.saude.gov.br/bvs/saudelegis/cns/2013/res0466_12_12_2012.html. Acesso em: 03 nov. 2020.

11. OLIVEIRA LM, et al. Qualidade de Vida e Espiritualidade de Pacientes com Doença Renal Crônica: Análise Pré e Pós Transplante. Brasileira de Enfermagem, 2020; 73: 1-7.

12. PAULETTO MR, et al. Transplante Renal: Percepção de Pacientes em Hemodiálise Fora da Lista de Espera. REUFSM, 2016; 6: 154-163.

13. PESTANA JOM, et al. Transplante Renal: Manual Prático. 1 ed. São Paulo: Balieiro, 2014.

14. RIBEIRO J, et al. Editorial: Saturação da Análise na Investigação Qualitativa: Quando Parar de Recolher Dados? Revista Pesquisa Qualitativa, 2018; 6: 1-5.

15. ROCHA HC, et al. À espera do transplante renal: sentimentos e expectativas. Revista Ciência, cuidado e saúde, 2018; 17(4): 1-7.

16. RODRIGUES KA, et al. Repercussões Biopsicossociais em Pacientes Submetidos a Tratamento Hemodialítico. Research, Society and Development, 2020; 9(3):1-23.

17. SOCIEDADE BRASILEIRA DE NEFROLOGIA. Censo-2019: censo de diálise no Brasil. Disponível em: http://www.sbn.org.br/Censo/censo01.

18. SOUZA AM, et al. Transplante renal: vivência de homens em hemodiálise inscritos na lista de espera. Rev Rene, 2015; 16(1): 11-20.

19. VALERI AM, et al. Presentation and Outcomes of Patients with ESKD and COVID-19. JASN, 2020 2020; 31 (7): 14091415.

20. VERONESE FV, et al. Nefrologia na Prática Clínica. 1 ed. São Paulo: Balieiro, 2019. 